\title{
Obesity impairs male fertility through long- term effects on spermatogenesis
}

\author{
Yan-Fei Jia ${ }^{1 \dagger}$, Qian Feng ${ }^{1 \dagger}$, Zheng-Yan Ge ${ }^{2}$, Ying Guo ${ }^{3,4}$, Fang Zhou ${ }^{3,4}$, Kai-Shu Zhang ${ }^{3,4}$, Xiao-Wei Wang ${ }^{4}$, \\ Wen-Hong Lü ${ }^{4}$ Xiao-Wei Liang ${ }^{4}$ and Yi-Qun Gu $u^{3,4^{*}}$
}

\begin{abstract}
Objective: This study aimed to investigate the effect and possible underlying mechanisms of high-fat diet-induced obesity on spermatogenesis in male rats.

Methods: A total of 45 male rats were randomly divided into control ( $n=15$, normal diet) and obesity groups ( $n=30$, high-fat diet) and were fed for 16 weeks. Body weight and organ indexes were determined after sacrifice. Indicators of reproductive function, including sperm count, sperm motility, apoptosis of spermatogenic cells, and oxidative stress levels, were measured. Serum metabolic parameters and reproductive hormones were also assayed.

Results: Compared with the control group, epididymal sperm motility in the obese rats was significantly decreased $(P<0$. 01). Morphological analysis of the obesity group showed vacuolar changes in seminiferous tubules, spermatogenic cell dysfunction, and increased apoptosis of spermatogenic cells in testicular tissue $(P<0.05)$. The calculated free testosterone (CFT) concentration in serum was decreased $(P<0.05)$, whereas the serum sex hormone-binding globulin (SHBG) level was significantly increased $(P<0.01)$. The superoxide dismutase $(\mathrm{SOD})$ concentration decreased and the malondialdehyde (MDA) concentration increased in testis tissues; however, neither changes were statistically significant $(P>0.05)$.
\end{abstract}

Results: Nutritional obesity can damage spermatogenesis in male rats due to long-term effects on spermatogenesis.

Keywords: Obesity, Spermatogenesis, Sex hormone-binding globulin, Testosterone

\section{Background}

Obesity refers to excessive accumulation of body fat, which has a negative impact on health. According to the World Health Organization (WHO), a body mass index (BMI) of $25-29.9 \mathrm{~kg} / \mathrm{m}^{2}$ is defined as overweight, while a BMI of $30 \mathrm{~kg} / \mathrm{m}^{2}$ is defined as obesity. The incidence of overweight and obesity has sharply increased [1]. Relevant statistical data show that the obese population has doubled worldwide from 1980 to 2008, and more than $10 \%$ of the population is obese [2]. The prevalence of obesity has continued to rise according to subsequent surveys, with the most recent estimate indicating that $35.2 \%$ of men and $40.4 \%$ of women are obese [3].

\footnotetext{
*Correspondence: yqgu90@126.com

${ }^{\dagger}$ Equal contributors

${ }^{3}$ Graduate School of Peking Union Medical College, No. 9 Dongdansantiao, Dongcheng District, Beijing 100730, People's Republic of China

${ }^{4}$ National Health and Family Planning Key Laboratory of Male Reproductive Health, Department of Male Clinical Research, National Research Institute for Family Planning, Beijing 100081, People's Republic of China

Full list of author information is available at the end of the article
}

Obesity is well documented to be linked to diseases such as type 2 diabetes mellitus, cardiovascular disease, cancers, and sleep apnea syndrome $[4,5]$. Recently, the effect of obesity on fertility has been extensively investigated. However, current studies have principally focused on the effects of obesity on the reproductive function of females or female animals, while males or male animals are poorly studied [6]. Additionally, while most reports have examined obesity in relation to reproductive function, the underlying mechanisms have not been elucidated $[7,8]$. In addition, conclusions on the effects of obesity on semen parameters and reproductive hormones have differed [9] due to the many factors that may impact male fertility. For example, a meta-analysis performed by MacDonald et al. found no statistically significant association between BMI and semen parameters [10], while a study performed by Sermondade et al. found a significant J-shaped association between BMI and an abnormal sperm count [11]. This study aimed to investigate spermatogenesis in male rats with obesity

(C) The Author(s). 2018 Open Access This article is distributed under the terms of the Creative Commons Attribution 4.0 International License (http://creativecommons.org/licenses/by/4.0/), which permits unrestricted use, distribution, and reproduction in any medium, provided you give appropriate credit to the original author(s) and the source, provide a link to the Creative Commons license, and indicate if changes were made. The Creative Commons Public Domain Dedication waiver (http://creativecommons.org/publicdomain/zero/1.0/) applies to the data made available in this article, unless otherwise stated. 
induced by high-fat diet administration to minimize experimental bias and identify possible mechanisms.

\section{Methods \\ Animals}

Six-week-old male Sprague-Dawley rats were provided by Vital River Laboratory Animal Technology Co., Ltd. (Beijing, China). The rats had a body weight of $130.43 \pm$ $7.15 \mathrm{~g}$. They were maintained on a 12 -h day/12-h night schedule (lights on from 19:00 to 07:00 h). Temperature and humidity were maintained at $22 \pm 1{ }^{\circ} \mathrm{C}$ and $60 \%$, respectively. Food and water were provided ad libitum, and each cage contained 5 rats. We tried our best to minimize animal suffering, and $\mathrm{CO}_{2}$ inhalation was used for euthanasia.

\section{Experimental design}

A total of 45 male rats were enrolled in this study and randomly divided into two groups, namely, the control group ( $n=15$, normal diet) and the obesity group $(n=30$, highfat diet), which received a normal diet and a high-fat diet, respectively. The high-fat formula was as follows [12]: 10\% lard oil, $10 \%$ sucrose, $1.5 \%$ cholesterol, $0.5 \%$ bile salt, $5 \%$ yolk powder, and $73 \%$ normal feed. The body weights and lengths of the rats were measured each week for 16 successive weeks. At the 16th week, the rats in the lower quartiles for weight gain $(n=8)$ were excluded from the obesity group. As the rats with body weights in the bottom quartile tended to exhibit obesity resistance, they were also excluded, and 22 obese rats were ultimately analyzed. To ensure appropriate grouping, a comparison of general status was performed between the two groups. The general growth status and metabolic parameters of the two groups were compared at the end of the 16th week.

After being fed with the respective diets for 16 weeks, all rats were anesthetized with $\mathrm{CO}_{2}$. Blood samples were obtained from the abdominal aorta, centrifuged (2400 rpm for $20 \mathrm{~min}$ at $4{ }^{\circ} \mathrm{C}$ and frozen at $-70{ }^{\circ} \mathrm{C}$ ) and were used to measure serum hormone levels [luteinizing hormone ( $\mathrm{LH})$, total testosterone TT), estradiol $\left(\mathrm{E}_{2}\right)$, and sex hormone-binding globulin (SHBG)]. Testicular histology, apoptosis of spermatogenic cells, and antioxidant status of the testis tissues were analyzed. Sperm suspensions from the cauda epididymis were used to determine sperm counts and motility.

\section{Body index and organ index assessments}

Bilateral testes, bilateral epididymides, and visceral fat (surrounding the kidney, testicles and omentum majus) were obtained and weighed. The relevant parameters were determined as follows: Lee index $=[$ weight $(\mathrm{g}) \times$ $10^{3} /$ body length $\left.(\mathrm{cm})\right]^{1 / 3}$; fat coefficient $=[$ visceral fat weight $(\mathrm{g}) \times 100 \% /$ body weight $(\mathrm{g})]$; and testicular coefficient $=[$ testicular weight $(\mathrm{g}) \times 100 \% /$ weight $(\mathrm{g})]$.

\section{Serum biochemical and hormone assays}

Serum SHBG was determined using an enzyme-linked immunosorbent assay (ELISA) kit obtained from Beijing Northern Biological Technology Research Institute (Beijing, China). Serum LH, T, and $\mathrm{E}_{2}$ were measured with radioimmunoassays (RIAs) using a kit obtained from Beijing Northern Biological Technology Research Institute (Beijing, China). Serum free testosterone (FT) was calculated using the Vermeulen formula:

$$
\begin{aligned}
c F T= & {[T-23.43 F T] /[S H B G-(T-23.43 F T)] } \\
& \times 10^{-9} \mathrm{~mol} / \mathrm{L} .
\end{aligned}
$$

\section{Histological examination}

Small pieces of testis were fixed in Bouin's solution and $70 \%$ ethanol, dehydrated in graded ethanol, fixed with $10 \%$ formalin solution for $48 \mathrm{~h}$, and treated with mixed decalcifying fluid. After dehydration with alcohol, the femoral heads were embedded with paraffin, cut into 5$\mu \mathrm{m}$ sections, and stained with HE. Cell morphology was observed under a light microscope and evaluated with Johnsen scoring [13, 14]. The histological criteria for modified Johnsen scoring are as follows: full spermatogenesis (score 10), slightly impaired spermatogenesis, many late spermatids, disorganized epithelium (score 9), less than five spermatozoa per tubule, few late spermatids (score 8), no spermatozoa, no late spermatids, many early spermatids (score 7), no spermatozoa, no late spermatids, few early spermatids (score 6), no spermatozoa or spermatids, many spermatocytes (score 5), no spermatozoa or spermatids, few spermatocytes (score 4), spermatogonia only (score 3), no germinal cells, Sertoli cells only (score 2), and no seminiferous epithelium (score 1).

\section{Sperm count and motility}

Sperm from the right cauda epididymis with a length of $1.5 \mathrm{~cm}$ were obtained. Internal rinsing with $1.0 \mathrm{ml}$ of modified M199 medium was performed at $37{ }^{\circ} \mathrm{C}$, and the samples were incubated for $30 \mathrm{~min}$ in a $37{ }^{\circ} \mathrm{C}$ water bath with vibration to induce the sperm to swim. Then, a $15-\mu \mathrm{l}$ sperm suspension was extracted for sperm count and motility analysis using a Hamilton-Thorne Sperm Analyzer (HTM-IVOS). The sperm count per $\mathrm{ml}$ in the suspension from a unilateral epididymis was then calculated.

\section{Assessment of spermatogenic cell apoptosis}

The TUNEL method was used to label the 3'-end of fragmented DNA in the apoptotic spermatogenic cells. 
The procedure was performed using Roche's TUNEL chemical staining method (Roche, SWISS, Cat. No. 11684817910) [15]. The brownish-orange particles in the cell nucleus observed under a microscope were classified as apoptotic cells. The apoptosis index (AI) was determined as follows: 500 cells were selected from five highpower fields from each section, and $\mathrm{AI}=$ apoptotic cell number $/ 500 \times 100 \%$.

\section{Antioxidant status evaluation}

The kits for assessing testis antioxidation status, including superoxide dismutase (SOD) [16] and malondialdehyde (MDA) [17] concentrations, were purchased from Nanjing Jiancheng Bioengineering Institute (Nanjing, China). Testis tissues were isolated and crushed with liquid nitrogen, a homogenate was prepared, and the remaining procedures were performed following the kit protocols.

\section{Statistical analysis}

Statistical analysis was performed using the SPSS 13.0 software package (Chicago, IL, USA). Student's t-tests or Mann-Whitney tests were used to compare the results between the two groups. The results are presented as the mean \pm s.e.m. in all cases, and $P<0.05$ was considered statistically significant.

\section{Results}

\section{General growth status and metabolic parameters}

The results showed that compared with those in the control group, the Lee index and fat coefficient level of the nutritional obesity rats were significantly increased $(P<0.05)$, whereas the testis coefficient was significantly decreased $(P<0.05)$. No obvious difference was found in body length between the two groups, indicating that the group division was reasonable (Table 1).

Table 1 General growth status and metabolic parameters

\begin{tabular}{|c|c|c|c|c|c|}
\hline & Weight & Length & Lee index & $\begin{array}{l}\text { Fat } \\
\text { coefficient }\end{array}$ & $\begin{array}{l}\text { Testis } \\
\text { coefficient }\end{array}$ \\
\hline & (g) & $(\mathrm{cm})$ & (\%) & (\%) & (\%) \\
\hline Control & 552.90 & 26.50 & 0.31 & 4.38 & 0.63 \\
\hline$n=15)$ & \pm 7.76 & \pm 0.94 & \pm 0.01 & \pm 0.96 & \pm 0.07 \\
\hline Obesity & 619.80 & 26.86 & 0.32 & 5.02 & 0.55 \\
\hline$(n=22)$ & \pm 7.56 & \pm 0.58 & \pm 0.01 & \pm 0.71 & \pm 0.06 \\
\hline$P$ value & $0.000^{* *}$ & 0.198 & $0.046^{*}$ & $0.039^{*}$ & $0.001^{* *}$ \\
\hline
\end{tabular}

The data are presented as the mean \pm s.e.m. ${ }^{*} P<0.05,{ }^{* *} P<0.01$ : statistical significance compared with the control group; Weight: body weight; length: body length; Lee index $=\left[\text { weight }(\mathrm{g}) \times 10^{3} / \text { Body length }(\mathrm{cm})\right]^{1 / 3}$; Fat coefficient $=[$ visceral fat weight $(\mathrm{g}) \times 100 \% /$ body weight $(\mathrm{g})]$; Testicular coefficient $=$ [testicular weight $(\mathrm{g}) \times 100 \% /$ weight $(\mathrm{g})]$; and s.e.m.,: standard error of the mean

\section{Sperm concentration and motility}

To clarify the effect of obesity on the number and viability of sperm, sperm concentration and motility were detected. The concentrations of sperm extracted from the epididymis were $23.40 \pm 9.72 \times 10^{6} / \mathrm{ml}$ and $24.64 \pm 7.16 \times$ $10^{6} / \mathrm{ml}$ in the two groups, with no significant difference $(P>0.05)$. As illustrated in Fig. 1, sperm motility [(36.40 $\pm 9.17) \%$ vs $(14.36 \pm 7.67) \%]$ was significantly decreased in the obesity group compared with the control group $(P<0.01)$. The results indicated that obesity did not reduce the number of sperm but caused a marked decline in sperm viability.

\section{Histological examination results}

To assess the morphology of spermatogenesis and spermatogenic cells, histological examination was performed. HE staining demonstrated vacuolation in the seminiferous tubules and structural dysfunction in the spermatogenic cells or detachment of germ cells from the basement membrane in the obesity group (Fig. 2a, b). No significant difference was found in Johnsen scores $[(9.14 \pm 0.14)$ vs $(8.86 \pm 0.09)](P>0.05)$ between the two groups (Fig. 2c). We concluded that the short-term influence of obesity on testicular function may not be very obvious; however, long-term effects may damage spermatogenic function.

\section{Ai}

To observe the effects of obesity on spermatogenic cell apoptosis, TUNEL assay was performed. The AI of spermatogenic cells (Fig. 3a, b) was significantly increased in the obesity group compared with the control group [ 5 . $95 \pm 0.49) \%$ vs $(8.61 \pm 1.05) \%](P<0.05)$ (Fig. 3c). The results suggest that obesity may promote testicular germ cell apoptosis.

\section{Reproductive hormone assays}

Regarding the effect of obesity on male reproductive hormones, serum cFT concentrations were decreased, and serum SHBG levels were increased $(P<0.05)$ in the obesity group. Although serum $\mathrm{T}$ levels decreased in the obesity group, no statistically significant differences were found between the two groups (Table 2).

\section{Oxidative stress assessment}

To determine the effect of obesity on oxidative stress, the concentrations of SOD and MDA in the testis homogenate were determined. The SOD and MDA concentrations of the testicular homogenate were $[(64.8 \pm 10.2)$ vs $(56.6 \pm 14.4) \mathrm{U} / \mathrm{ml}]$ and $[(3.0 \pm 0.7)$ vs $(4.0 \pm 0.8)$ $\mathrm{nmol} / \mathrm{ml}]$ in the two groups $(P>0.05)$ and $(P>0.05)$, respectively (Fig. 4). The results indicated that the SOD concentration decreased while the MDA concentration 

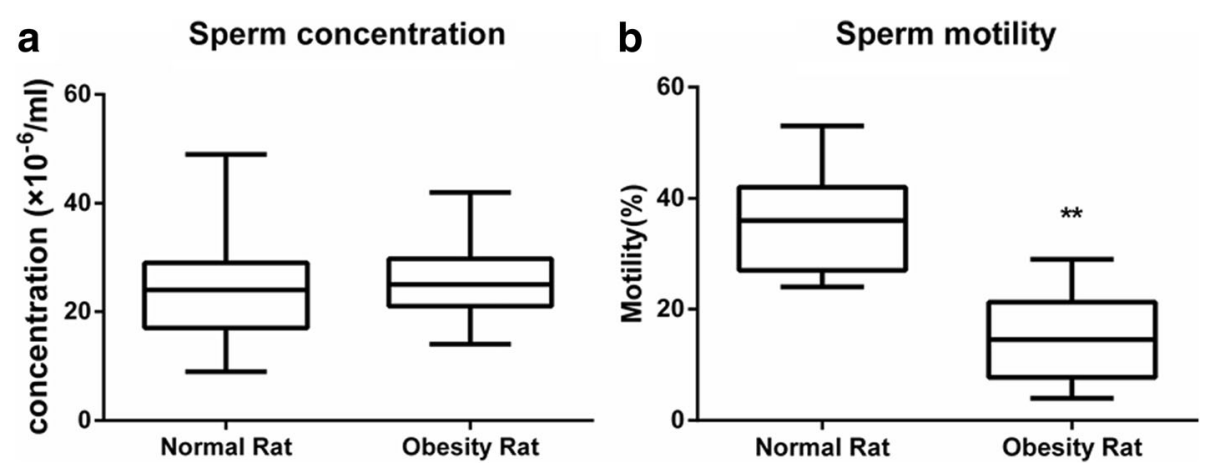

Fig. 1 Comparison of sperm concentration (a) and motility (b) between the two groups. The data are presented as the mean \pm s.e.m.; $* P<0.05$ and ${ }^{*} P<0.01$

increased; however, neither change was statistically significant.

\section{Discussion}

Obesity is a chronic metabolic disease caused by interactions of various genetic and environmental factors. Interestingly, in the past 50 years, along with the annually increasing trend in human obesity, fertility has shown a parallel decreasing trend [18]. Several studies have indicated that a higher BMI is associated with significant decreases in sperm concentration [19-21]. Investigators have attempted to investigate the relationship between obesity and fertility decline; however, no consensus has been reached.

Currently, no unified standard is available for evaluating obese rats. In 1929, MO Lee [22] proposed the Lee index to evaluate obesity in rats, which is the most commonly used method to evaluate obese rats. In a dietinduced model of obesity reported by Levin, rats became obesity-resistant with high-fat diet administration [23], and differences were found in their energy, endocrine, fat and glutamic acid (GLU) metabolism. Based on the

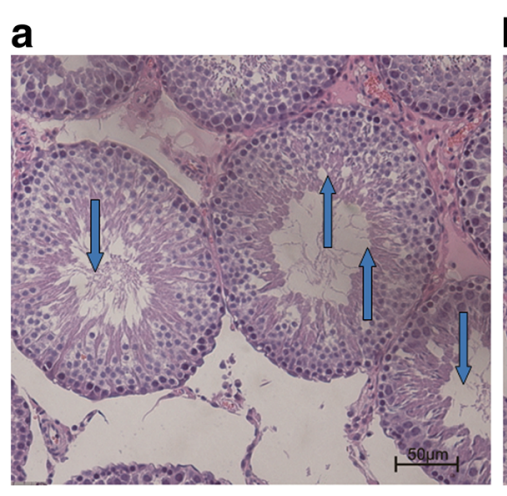

\section{b}

C


Fig. 2 HE staining of testicular tissues $(\times 20)$ and comparison of sperm Johnsen scores between the two groups. a control group; b, obesity group; $\mathbf{c}$ the data are presented as the mean \pm s.e.m.; ${ }^{*} P<0.05$ and ${ }^{*} P<0.01$ 


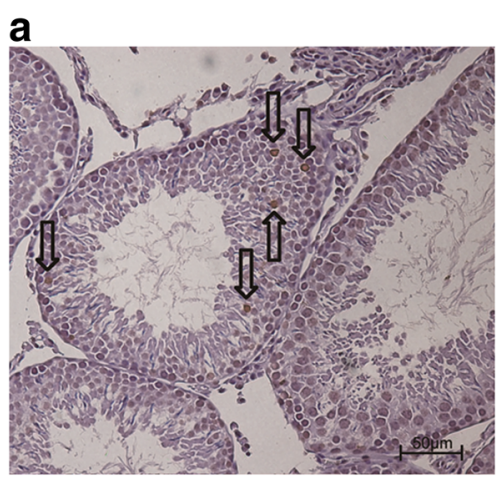

C

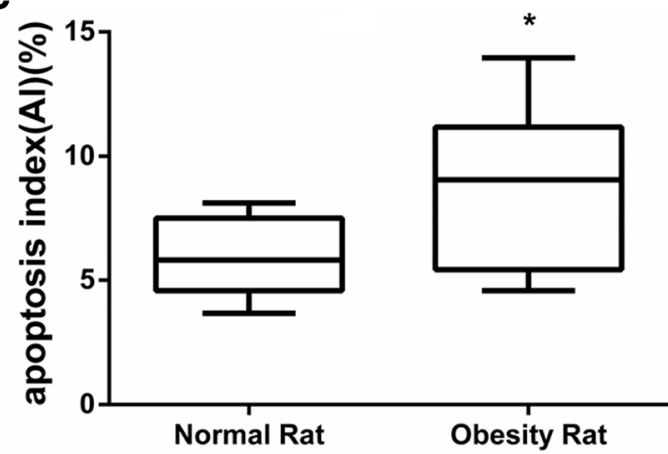

Fig. 3 Apoptosis of spermatogenic cells in testicular tissues and comparison of the apoptosis index between the two groups $(\times 20$, arrows indicate apoptotic cells). $\mathbf{a}$ control group; $\mathbf{b}$ obesity group; $\mathbf{c}$ the data are presented as the mean \pm s.e.m.; ${ }^{*} P<0.05$ and ${ }^{* *} P<0.01$

relevant literature and the Lee index, one-fourth of the rats in the high-fat diet group were excluded in our study because they were obesity-resistant. The remaining three-quarters of the rats were classified as the obesity group [24]. Our results demonstrated successful generation of the obese rat model.

Currently, the effect of male obesity on sperm count, motility, and morphology in humans is controversial. A review found that up to 2015, progressively reduced motility was reported in 13 of 35 articles, while a decreased sperm count with normal morphology was reported in only 9 of 29 papers [6]. However, two recent metaanalyses including 14 and 21 studies demonstrated an increased risk of azoospermia or oligozoospermia in

Table 2 Reproductive hormone levels in the two groups

\begin{tabular}{llllll}
\hline & $\begin{array}{l}\mathrm{LH} \\
(\mathrm{mlU} / \mathrm{ml})\end{array}$ & $\begin{array}{l}\Pi \mathrm{ng} / \mathrm{ml}) \\
(\mathrm{pg} / \mathrm{ml})\end{array}$ & $\begin{array}{l}\mathrm{E}_{2} \\
(\mathrm{nmol} / \mathrm{L})\end{array}$ & $\begin{array}{l}\mathrm{CFT} \\
(\mathrm{ng} / \mathrm{ml})\end{array}$ \\
\hline Control & 3.44 & 0.80 & 4.49 & 50.35 & 0.011 \\
$(n=15)$ & \pm 2.75 & \pm 0.76 & \pm 3.60 & \pm 6.26 & \pm 0.010 \\
Obesity & 3.20 & 0.59 & 4.39 & 85.13 & 0.003 \\
$(n=22)$ & \pm 2.76 & \pm 0.51 & \pm 2.45 & \pm 9.13 & \pm 0.002 \\
P value & 0.799 & 0.356 & 0.926 & $0.000^{* *}$ & $0.031^{*}$
\end{tabular}

The data are presented as the mean \pm s.e.m. ${ }^{*} P<0.05,{ }^{* *} P<0.01$ : statistical significance compared with the control group; $L H$ luteinizing hormone, $\Pi$ total testosterone, E2 estradiol, SHBG sex hormone-binding globulin, CFT calculated free testosterone, and s.e.m. standard error of the mean

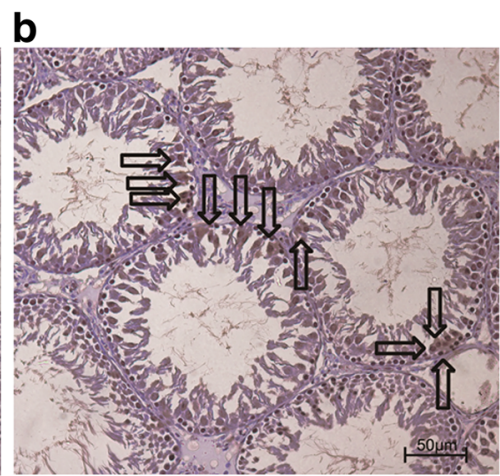

* $P<0.05$ and ${ }^{* *} P<0.01$
* $P$ the two groups $(\times 20$,

overweight or obese males $[25,26]$. The results from this study indicated that obesity induced by a high-fat diet can change the histomorphology of seminiferous tubules, which may not have obvious effects on male fertility immediately, but the long-term effects on spermatogenesis induced by obesity may impair male fertility.

Due to gene polymorphisms in the population, many factors (e.g., smoking, alcohol consumption, and medication use) that can affect seminal parameters are often overlooked. In addition, sample selection bias can lead to inconsistent conclusions regarding the impact of obesity on sperm. This study, by controlling various confounding factors, revealed that obesity reduced sperm motility without changing the sperm count, which is consistent with previous reports [25]. The possible mechanism may be damage to the integrity of sperm cell membranes, sperm cell DNA, and sperm mitochondria induced by excessive reactive oxygen species (ROS) [27, 28].

Apoptosis is an autonomous programmed cell death process that is stimulated under specific conditions and is regulated by various genes. We found that the AI of the spermatogenic cells increased significantly in the obesity group. A recent study found that apoptosis of testicular spermatogenic cells is one of the major causes of male subfertility [29]. Cell apoptosis is predominantly regulated and controlled by the 
a

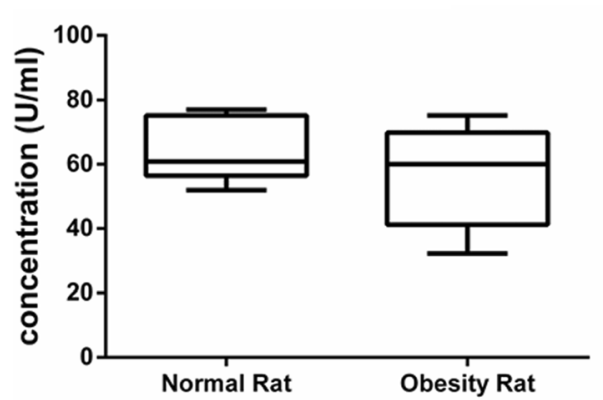

b

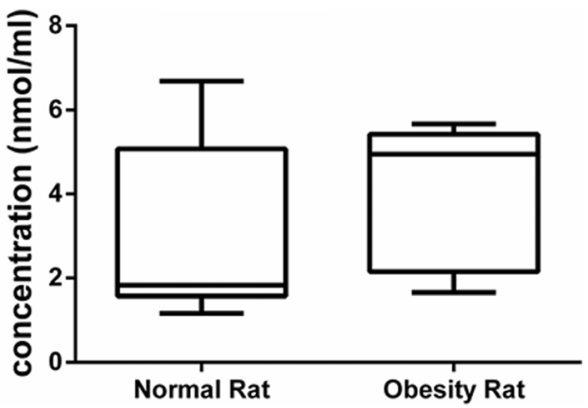

Fig. 4 Comparison of the concentrations of SOD (a) and MDA (b) in the testis homogenate between the two groups. SOD: superoxide dismutase, MDA: malondialdehyde; the data are presented as the mean \pm s.e.m.; ${ }^{*} P<0.05$ and ${ }^{* *} P<0.01$

homeostasis of $\mathrm{Bax}$ and $\mathrm{Bcl}-2$. When the $\mathrm{Bcl}-2 / \mathrm{Bax}$ ratio is disrupted, downstream caspase signaling pathways are activated, resulting in apoptosis. A high-fat diet has been reported to increase Bax and caspase-3 expression but reduce $\mathrm{Bcl}-2$ expression in the testis [30]. Therefore, based on our results, obese rats exhibited increased spermatogenic cell apoptosis due to imbalances of $\mathrm{Bcl}-2 / \mathrm{Bax}$. Furthermore, obesity resulted in lipid metabolic disorders and hyperlipidemia, which may increase the stress response of the endoplasmic reticulum. Therefore, the incidence of spermatogenic cell apoptosis is further increased [31, 32] via increased GRP78 mRNA and protein expression.

Mammalian reproductive function is predominantly controlled and regulated by the hypothalamus-pituitarytestis (HPT) axis. Male reproductive endocrinology is principally composed of three groups of hormones, including GnRH, GnIH, LH, FSH, and T. T is one of the major sex hormones in males and has an important role in the HPT axis. Hypothalamic hormones are intricately associated with obesity-induced physiological changes, indicating a mutual cause-effect relationship between obesity and gonadal hormone decline [33]. In a study with 3219 European males, Fui and other investigators found that the TT and FT levels in obese males were lower than those in normal-weight males. Another study with 314 Asian males reached the same conclusion [34]. Camacho found that obesity reduces testosterone, low testosterone levels can promote male obesity, and testosterone increases after weight loss [35]. Compared with rats fed a normal diet, rats fed a high-fat diet had lower testosterone levels. When these rats were fed a normal diet, their testosterone levels returned to normal [35]. Although biologically active serum FT only accounts for $2 \%$ of TT, it is directly involved in functional activities, such as the development of male secondary sex characteristics, maintenance of spermatogenesis and sexual desire [36]. As a diagnostic marker for male hypogonadism, the serum cFT level exhibits better sensitivity than the serum TT level [37].

SHBG is a blood transport protein for testosterone and estradiol. Its synthesis and secretion are regulated by androgen and estrogen. Serum SHBG may exert direct or indirect effects on androgen conversion and metabolism, and it regulates GLU homeostasis and fatty acid metabolism. In this experiment, our results confirmed decreases in serum TT and cFT levels and an increase in the serum SHBG concentration in the obese rats. Therefore, we hypothesize that serum SHBG is the key factor in reducing serum cFT levels, and obese rats may develop mild primary hypogonadism (reduced serum TT and cFT, increased SHBG). Primary hypogonadism in the obese rats is likely the initiating factor for alterations in the HPT axis.

Oxidative stress is highly correlated with a wide variety of inflammatory and metabolic disease states, including obesity. Oxidative stress is highly correlated with cumulative damage in the body induced by free radicals that are inadequately neutralized by antioxidants, and oxidative damage is aggravated by decreases in antioxidant enzyme activities, such as those of SOD, catalase (CAT), and glutathione S-transferase (GST) [38]. Evidence suggests that there are many sources of oxidative stress in obesity [39]. In our study, to determine the effect of obesity on oxidative stress, the concentrations of SOD and MDA in testis homogenate were determined.

SOD, which protects cells from free radical damage by ROS, is an important enzyme that protects against injuries caused by internal and external superoxide ions. MDA is an aldehyde generated in the process of lipid peroxidation caused by free radicals. MDA indicates cell membrane damage and reflects the severity of an oxygen radical attack on reactive cells and the levels of free radical metabolism in vivo. Decreased SOD and increased MDA can trigger oxidative stress, causing cell damage and even death. This study found decreased SOD levels 
and increased MDA levels in the testicular tissues of obese rats, demonstrating that the oxidative stress level of testis tissues in obese rats is increased and may impact sperm motility. Several possible explanations may account for these findings: obesity is associated with elevated serum free fatty acids, and unsaturated fatty acids are susceptible to attacks by ROS, producing peroxidation and subsequently resulting in decreased SOD levels and MDA accumulation, which is ultimately reflected by an increased oxidative stress level [40].

\section{Conclusion}

The rats with obesity induced by high-fat diet administration exhibited lipid metabolism dysfunction and altered reproductive hormone levels as well as increased oxidative stress levels in testis tissues, leading to mild primary hypogonadism. Meanwhile, the normal function of the HPT axis is maintained in the short-term through a corresponding feedback mechanism. However, the long-term effects of obesity may cause a decline in male fertility.

\section{Abbreviations \\ Al: apoptosis index; BMI: body mass index; CFT: Calculated free testosterone; CVD: Cardiovascular disease; DM: Diabetes mellitus; $\mathrm{E}_{2}$ : Estradiol; FT: Free testosterone; HPT: Hypothalamus-pituitary-testis; HTM-IVOS: Hamilton-Thorne Sperm Analyzer; LH: Luteinizing hormone; MDA: Malondialdehyde; ROS: Reactive oxygen species; SHBG: Serum sex hormone-binding globulin; SOD: Ssuperoxide dismutase; SPF: Specific-pathogen-free; T: Testosterone; TT: Total testosterone; WHO: World Health Organization}

\section{Funding}

This work was financed by the National "Twelfth Five-Year" Plan for Science and Technology Support (2012BAI32B03 for purchasing most of the experimental reagents and materials, as well as the labor costs for the researchers and the fee for some antibodies).

\section{Availability of data and materials}

The datasets for the current study are available from the corresponding author upon reasonable request.

\section{Authors' contributions}

YFJ and QF collected the data, performed the statistical analysis, interpreted the results, and drafted and revised the manuscript. YFJ and YQG conceived of and designed the study. ZYG, YG, FZ, KSZ, XWW, WHL, and XWL participated in data collection and performed the laboratory measurements. All authors read and approved the final manuscript.

\section{Competing interest}

The authors declare that they have no competing interests.

\section{Ethics approval and consent to participate}

Experimental procedures were performed in accordance with the Ethical Principles in Animal Research and were approved by the National Research Institute for Family Planning Ethics Committee for Animal Research. The approval number is 2015070502.

\section{Publisher's Note}

Springer Nature remains neutral with regard to jurisdictional claims in published maps and institutional affiliations.

\section{Author details}

'Lanzhou University Second Hospital, Lanzhou 730020, People's Republic of China. ${ }^{2}$ Xiyuan Hospital, China Academy of Traditional Chinese Medicine,
Beijing 100091, People's Republic of China. ${ }^{3}$ Graduate School of Peking Union Medical College, No. 9 Dongdansantiao, Dongcheng District, Beijing 100730, People's Republic of China. ${ }^{4}$ National Health and Family Planning Key Laboratory of Male Reproductive Health, Department of Male Clinical Research, National Research Institute for Family Planning, Beijing 100081, People's Republic of China.

Received: 24 October 2016 Accepted: 4 May 2018

Published online: 16 May 2018

\section{References}

1. Matheus AS, Tannus LR, Cobas RA, Palma CC, Negrato CA, Gomes MB, Impact of diabetes on cardiovascular disease: an update. Int J Hypertens. 2013;2013:653789.

2. Finucane MM, Stevens GA, Cowan MJ, et al. National, regional, and global trends in body-mass index since 1980: systematic analysis of health examination surveys and epidemiological studies with 960 country-years and 9.1 million participants. Lancet. 2011;377:557-67.

3. Kahn BE, Brannigan RE. Obesity and Male infertility. Curr Opin Urol. 2017;27. 441-5.

4. Haslam DW, James WP. Obesity. Lancet. 2005;366:1197-209.

5. Poulain M, Doucet M, Major GC, et al. The effect of obesity on chronic respiratory diseases: pathophysiology and therapeutic strategies. CMAJ. 2006;174(9):1293.

6. Coviello AD, Legro RS, Dunaif A. Adolescent girls with polycystic ovary syndrome have an increased risk of the metabolic syndrome associated with increasing androgen levels independent of obesity and insulin resistance. J Clin Endocrinol Metab. 2006;91:492-7.

7. Landry D, Cloutier F, Martin LJ. Implications of leptin in neuroendocrine regulation of male reproduction. Reprod Biol. 2013;13:1-14.

8. Cabler S, Agarwal A, Flint M, du Plessis SS. Obesity: modern man's fertility nemesis. Asian J Androl. 2010;12:480-9.

9. McPherson NO, Lane M. Male obesity and subfertility, is it really about increased adiposity? Asian J Androl. 2015;17:450-8. https://doi.org/10.4103/ 1008-682X.148076. Pubmed:25652636.

10. MacDonald AA, Herbison GP, Showell M, Farquhar CM. The impact of body mass index on semen parameters and reproductive hormones in human males: a systematic review with meta-analysis. Hum Reprod Update. 2010; 16:293-311.

11. Tsao CW, Liu CY, Chou YC, Cha TL, Chen SC, Hsu CY. Exploration of the association between obesity and semen quality in a 7630 male population. Plos One. 2015;10(3):e0119458.

12. Dong $X$, Song $W, G$, $Z$, et al. Effects of Jiangtang Xiaozhi tablets on expression of NFKB, CYP. Int J Clin Exp Med. 2016;9:18373-8.

13. Atilgan $D$, Parlaktas $B S$, Uluocak $N$, et al. Weight loss and melatonin reduce obesity-induced oxidative damage in rat testis. Ther Adv Urol. 2013;2013: 836121.

14. Johnsen SG. Testicular biopsy score count-a method for registration of spermatogenesis in human testes: normal values and results in 335 hypogonadal males. Horm Res Paediatr. 1970;1:2-25.

15. Zhu B, Zheng YF, Zhang YY, et al. Protective effect of $L$-carnitine in cyclophosphamide-induced germ cell apoptosis. J Zhejiang Univ Sci B. 2015;16:780-7.

16. Peskin AAV, Winterbourn CC. A microtiter plate assay for superoxide dismutase using a water-soluble tetrazolium salt (WST-1). Clin Chim Acta. 2000;293:157-66.

17. Draper HH, Hadley M. Malondialdehyde determination as index of lipid peroxidation. Methods Enzymol. 1990;186:421-31.

18. Hammoud AO, Meikle AW, Reis LO, Gibson M, Peterson CM, Carrell DT. Obesity and male infertility: a practical approach. Semin Reprod Med. 2012; 30:486-95.

19. Chavarro JE, Toth TL, Wright DL, Meeker JD, Hauser R. Body mass index in relation to semen quality, sperm DNA integrity, and serum reproductive hormone levels among men attending an infertility clinic. Fertil Steril. 2010; 93:2222-31.

20. Hammiche F, Laven JS, Boxmeer JC, Dohle GR, Steegers EA, SteegersTheunissen RP. Sperm quality decline among men below 60 years of age undergoing IVF or ICSI treatment. J Androl. 2011;32:70-6.

21. Tunc O, Bakos HW, Tremellen K. Impact of body mass index on seminal oxidative stress. Andrologia. 2011;43:121-8. 
22. Lee MO. Determination of the surface area of the white rat with its application to the expression of metabolic results. Am J Phys. 1929;89:24-33.

23. Levin BE. Arcuate npy neurons and energy homeostasis in diet-induced obese and resistant rats. Am J Physiol-Reg I. 1999;276:R382-7.

24. Chang S, Graham B, Yakubu F, Lin D, Peters JC, Hill JO. Metabolic differences between obesity-prone and obesity-resistant rats. Am J Phys. 1990;259: R1103-10.

25. Sermondade N, Faure C, Fezeu L, et al. BMl in relation to sperm count: an updated systematic review and collaborative meta-analysis. Hum Reprod Update. 2013;19:221-31.

26. Sermondade N, Faure C, Fezeu L, Lévy R, Czernichow S. Obesity-fertility collaborative group. Obesity and increased risk for oligozoospermia and azoospermia. Arch Intern Med. 2012;172:440-2.

27. Liu B, Ma D, Mao PF. Role of oxidative stress injury in male infertility. Natl J Androl. 2014:20:927-31.

28. Pasqualotto FF, Sharma RK, Pasqualotto EB, Agarwal A. Poor semen quality and Ros-TAC scores in patients with idiopathic infertility. Urol Int. 2008;81:263-70.

29. Garolla A, Torino M, Sartini B, et al. Seminal and molecular evidence that sauna exposure affects human spermatogenesis. Hum Reprod. 2013;28:877-85.

30. Mu Y, Yan WJ, Yin TL, Yang J. High-fat diet induces spermatogenesis dysfunction in male rats. J Med Res. 2015;44:88-91.

31. Xin W, Li X, Lu X, Niu K, Cai J. Involvement of endoplasmic reticulum stressassociated apoptosis in a heart failure model induced by chronic myocardial ischemia. Int J Mol Med. 2011;27:503-9.

32. Li CY, Dong ZQ, Lan XX, Zhang XJ, Li SP. Endoplasmic reticulum stress promotes the apoptosis of testicular germ cells in hyperlipidemic rats. Zhonghua Nan Ke Xue. 2015;21:402-7.

33. Rao PM, Kelly DM, Jones TH. Testosterone and insulin resistance in the metabolic syndrome and T2DM in men. Nat Rev Endocrinol. 2013;9:479-93.

34. Fui MNT, Dupuis P, Grossmann M. Lowered testosterone in male obesity: mechanisms, morbidity and management. Asian J Androl. 2014;16:223-31.

35. Camacho EM, Huhtaniemi IT, O'Neill TW, et al. Age-associated changes in hypothalamic-pituitary-testicular function in middle-aged and older men are modified by weight change and lifestyle factors. Eur J Endocrinol. 2013; 168:445-55.

36. Sharpe RM. Intratesticular factors controlling testicular function. Biol Reprod. 1984;30:29-49.

37. Liu TH, Yang RF, Kong XB, et al. Analysis of male serum total testosterone and serum free testosterone in different ages. Chin J Fam Plann Gynecotokol. 2014;6:16-8.

38. Blokhina O, Virolainen E, Fagerstedt KV. Antioxidants, oxidative damage and oxygen deprivation stress: a review. Ann Bot. 2003;91:179-94.

39. Vincent HK, Taylor AG. Biomarkers and potential mechanisms of obesityinduced oxidant stress in humans. Int J Obes. 2006:30:400-18.

40. Fang $X, X u$ QY, Jia C, Peng YF. metformin improves epididymal sperm quality and antioxidant function of the testis in diet-induced obesity rats. Zhonghua Nan Ke Xue. 2012;18:146-9.

\section{Ready to submit your research? Choose BMC and benefit from:}

- fast, convenient online submission

- thorough peer review by experienced researchers in your field

- rapid publication on acceptance

- support for research data, including large and complex data types

- gold Open Access which fosters wider collaboration and increased citations

- maximum visibility for your research: over $100 \mathrm{M}$ website views per year

At BMC, research is always in progress.

Learn more biomedcentral.com/submissions 